DOI: https://doi.org/10.24867/02IH02Vasiljevic

\title{
PLANIRANJE PUTANJE I IZVRŠAVANJE KRETANJA MOBILNOG ROBOTA U PRISUSTVU STATIČKIH I DINAMIČKIH PREPREKA
}

\section{PATH PLANNING AND MOTION EXECUTION OF MOBILE ROBOT IN PRESENCE OF STATIC AND DYNAMIC OBSTACLES}

\author{
Predrag Vasiljević, Fakultet tehničkih nauka, Novi Sad
}

\section{Oblast - MEHATRONIKA}

Kratak sadržaj - U ovom radu je prikazano na koji način je izvršeno planiranje putanje mobilnog robota $u$ prisustvu statičkih $i$ dinamičkih prepreka. Odabrana metoda za planiranje putanje je prikazana u drugom poglavlju i naziva se A* algoritam. U trećem poglavlju je objašnjeno izvršavanje kretanja $i$ upravljanje brzinom. Nakon toga, u četvrtom poglavlju je prikazana implementacija na mobilnom robotu pogonjenim sa tri omnidirekciona točka, kao i način testiranja planiranja putanje u prisustvu statičkih i dinamičkih prepreka.

Ključne reči: Mobilni robot, Planiranje putanje, Prepreke

Abstract - In this paper is presented method used for path planning for mobile robot in presence of static and dynamic obstacles. Selected method for path planning is presented in second chapter and it is called $A^{*}$ algorithm. In third chapter is explained motion execution and speed control. After that, in fourth chapter is presented implementation on mobile robot driven by three omnidirectional wheels, as well as testing method for path planning in presence of static and dynamic obstacles.

Keywords: Mobile robot, Path planning, Obstacles

\section{UVOD}

Jedan od glavnih razloga nastanka ovog rada je rešavanje problema planiranja kretanja mobilnog robota kojeg studenti prave da bi učestvovali na nacionalnom takmičenju EUROBOT. Do sada robot nije imao nikakvu predstavu o bilo kakvim preprekama na stolu na kojem se održava EUROBOT. Tako da je robot uvek išao po unapred zadatim tačkama, bez mogućnosti dinamičkog menjanja putanje tokom rada. U slučaju da robot naleti na protivničkog robota, on bi ga detektovao, uz pomoć senzora, i zaustavio se pa onda čekao dok se protivnički robot ne pomeri sa njegove trenutne putanje. Kako svaki tim može da ima najviše dva robota na stolu u toku meča to znači da se po njemu kreću četiri, ne tako mala, robota istovremeno. Kada se još uračunaju razne prepreke koje se nalaze na stolu vidi se da prostor kretanja nije tako veliki. Pritom se i sam taj prostor za kretanje dinamički menja tokom meča zbog prisustva protivničkog robota čije kretanje može biti različito od meča do meča.

\section{NAPOMENA:}

Ovaj rad proistekao je iz master rada čiji mentor je bio dr Milutin Nikolić, docent.
U ovom radu će biti prikazan jedan od načina planiranja kretanja u prisustvu statičkih i dinamičkih prepreka. Prvo će biti prikazan algoritam koji pronalazi putanju do željene pozicije, izbegavajući sve statičke i dinamičke prepreke. Biće prikazan i način kako smanjiti broj potrebnih tačaka putanje pronalaženjem svih prelomnih tačaka putanje i izdvajanjem samo onih koje su potrebne da se stigne do cilja.

Posle toga biće prikazano na koji način se određuje brzina i dužina puta potrebna za usporavanje ili ubrzavanje do određene brzine na osnovu dužine puta između početne $\mathrm{i}$ krajnje tačke, zadatog ubrzanja/usporenja, početne i krajnje zadate brzine. I na kraju, biće reči o samoj implementaciji i maketi robota koja je korišćenja za testiranje.

\section{A* ALGORITAM}

U ovom poglavlju biće dat kratak opis A* algoritma i na koji način se uz pomoć njega pronalazi putanja između dve tačke. Nakon toga, u prvom podpoglavlju biće prikazana simulacija ovog algoritma u MATLAB-u i neke od varijanti određivanja parametara koji se koriste u algoritmu. U simulaciji će biti prikazani primeri i za statičke i za dinamičke prepreke.

Posle ovoga, u drugom podpoglavlju, biće prikazano pronalaženje prelomnih tačaka. I u trećem, biće opisano kako se vrši izdvajanje samo onih prelomnih tačaka putanje koje su neophodne da se stigne do cilja.

Ideja je da se 2D prostor u kom se, u ovom slučaju, robot kreće podeli na manje prostorne ćelije, tj. polja (Slika 1), i da se za svaku ćeliju izračuna njeno rastojanje od cilja. Ovo je predstavljeno u vidu $\mathrm{H}$ parametra kojeg poseduje svaka ćelija. Takođe, svaka ćelija je još određena svojom pozicijom u 2D prostoru.

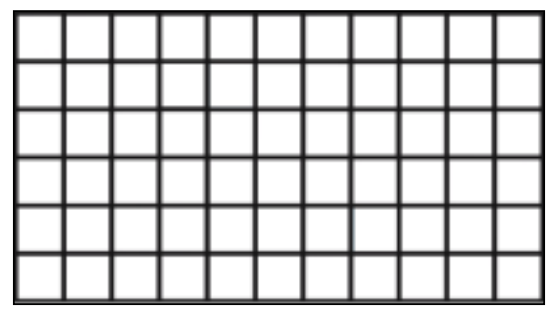

Slika 1. 2D prostor podeljen na prostorne ćelije

Pored ovog parametra $\mathrm{H}$ postoji još jedan parametar $\mathrm{G}$ koji predstavlja pređeni put od početne ćelije do ćelije za koju se računa ovaj parametar. Zadatak je minimizovati pređeni put od starta do cilja. To se postiže tako što se u 
svakom trenutku analizira ćelija sa najmanjim $\mathrm{F}$ koje predstavlja zbir parametara $\mathrm{H} \mathrm{i} \mathrm{G}$ :

$$
F(n)=H(n)+G(n)
$$

Traženjem najmanjih vrednosti parametara $\mathrm{H}$ i G, tokom pretrage prostora, dobija se najkraći put između početne $i$ željene ćelije za trenutno pretraženi broj ćelija.

Postupak je sledeći: Postoje dva skupa koja se popunjavaju ćelijama tokom pretrage prostora. Otvoreni skup, koji sadrži ćelije koje treba obići, i zatvoreni skup gde se nalaze ćelije koje su već obiđene. Dok se ne stigne do ciljne tačke iz otvorenog skupa se uzima ćelija sa najmanjim $\mathrm{F}$, prebacuje u zatvoreni skup i za susede te ćelije se računa F. Ti susedi se dodaju u otvoreni skup ukoliko već nisu u zatvorenom. Susedne ćelije su one ćelije koje se, u odnosu na posmatranu ćeliju, nalaze gore, dole, levo, desno i dijagonalno, i može ih biti najviše 8 . Tokom rada algoritma broj ćelija u zatvorenom skupu stalno raste, dok kod otvorenog raste i opada. $\mathrm{Za}$ računanje vrednosti $H$ parametra korišćenje su dve metode: modifikovani Manhattan distance i Euklidsko rastojanje.

\subsection{Simulacija $\mathrm{A}^{*}$ algoritma u MATLAB-u}

Simulacija u MATLAB-u je urađena uz pomoć grafika koji iscrtava sve zadate prepreke i polja koja se nalaze $u$ zatvorenom i otvorenom skupu tokom pretrage. Po završetku pretrage na grafiku se iscrtava putanja koja spaja početnu i željenu poziciju (Slika 2).

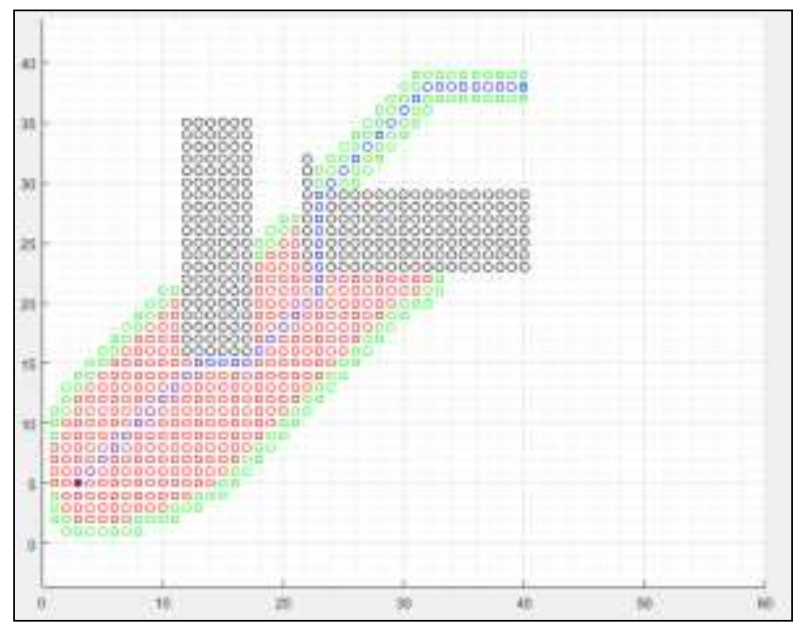

Slika 2. Prikaz dobijene putanje

$\mathrm{Na}$ slici 2 dat je grafik sa postavljenim statičkim preprekama u 2D prostoru na mestima koji su predstavljeni sa crnim krugovima. Početna pozicija se nalazi na mestu označenim sa tamno plavom zvezdicom, odnosno u donjem levom uglu na grafiku.

Željena pozicija se nalazi na mestu označenim sa svetlo plavom zvezdicom, tj. u gornjem desnom uglu na grafiku. Ćelije zatvorenog skupa se nalaze na mestima označenim sa crvenim kvadratićima, dok se ćelije otvorenog skupa nalaze na mestima označenim sa zelenim kvadratićima. Putanja je označena sa plavim kvadratićima.

Ako se desi da robotu, koji je već pronašao svoju putanju i trenutno je prati, drugi protivnički robot preseče put, senzori na njemu će to detektovati i dinamički ubaciti, u masku sa statičkim preprekama, objekat koji je detektovan. Nakon ovoga robot treba samo ponovo da izvrši pretragu do cilja i nađe novu putanju uz pomoć koje se izbegava protivnički robot. Primer ovoga je dat na slici 3.

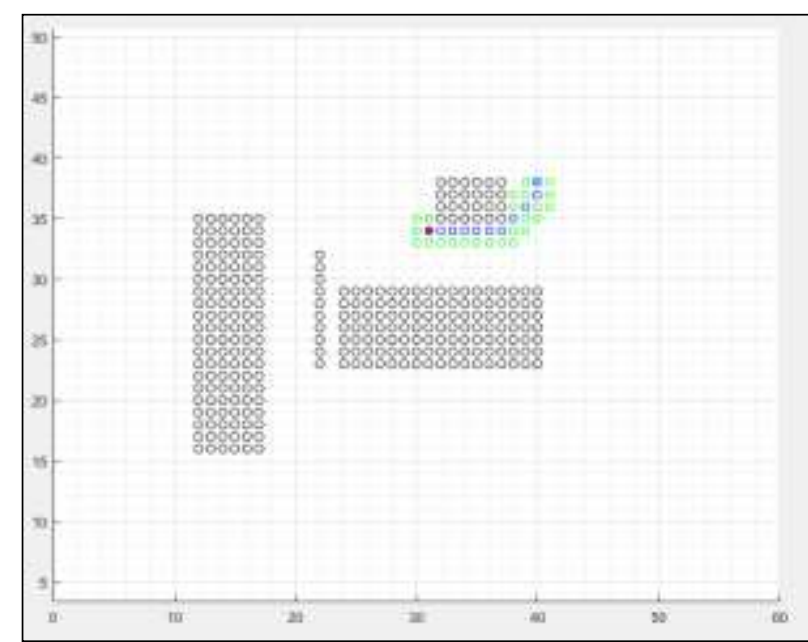

Slika 3. Detekcija nove dinamičke prepreke i pretraga nove putanje

\subsection{Traženje prelomnih tačaka putanje}

Da se robotu ne bi zadavale sve tačke pronađene putanje, potrebno je smanjiti broj tačaka tako što će se prvo pronaći sve prelomne tačke putanje, odnosno tačke gde putanja menja pravac. Ovo će biti urađeno tako što će se proći kroz sve tačke putanje i zapamtiti samo one tačke gde putanja menja pravac. Ovo traje zanemarljivo malo vremena, zato što se posmatraju samo ćelije na već određenoj putanji, i zato što se samo u trenucima promene pravca vrši pomćenje jedne tačke. Na slici 4 je prikazan rezultat jedne takve pretrage.

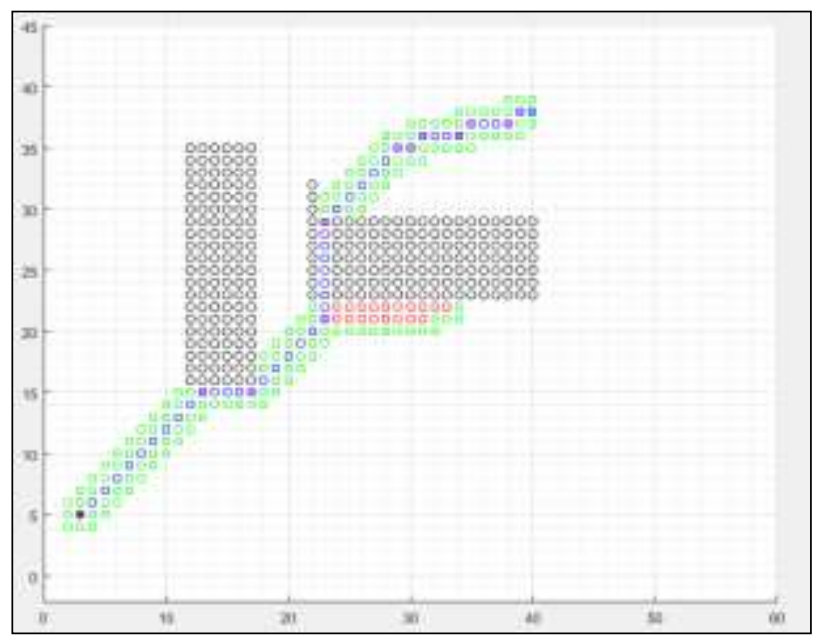

Slika 4. Prikaz prelomnih tačaka putanje

$\mathrm{Na}$ slici 4 je dat prikaz prelomnih tačaka putanje koje su na slici označene sa ljubičastim x znacima unutar plavih kvadratića koji predstavljaju putanju.

$\mathrm{Na}$ ovom grafiku se vidi da prelomnih tačaka ima 11, i da nisu potrebne baš sve ove tačke da bi se stiglo do željene pozicije, odnosno neke od njih se mogu i preskočiti. Ovaj zadatak je obrađen u narednom podpoglavlju 2.3. 


\subsection{Smanjenje broja prelomnih tačaka putanje}

Ovim postupkom se dobija konačan broj prelomnih tačaka. Smanjenje broja prelomnih tačaka će biti urađeno na sledeći način: Prvo se kreće od početne pozicije, i za nju se računa do koje najdalje prelomne tačke može da se pravolinijski stigne, iz posmatrane početne, a da se ne pređe preko prepreke. Kad se ta tačka nađe treba proveriti da li ona sa tog mesta može pravolinijski da dođe do bar dve sledeće prelomne tačke.

Ako može, nju treba uzeti za prvu prelomnu tačku, a ako ne može onda treba uzeti susednu tačku, koja se bira u zavisnosti gde se nalazi prepreka. I tada ta susedna tačka postaje prva prelomna tačka konačne putanje. Ako se desi da oko pronađene tačke ne postoji prepreka onda se ona odmah uzima da bude prva prelomna tačka putanje. Ovaj postupak se ponavlja dok se ne dođe do cilja.

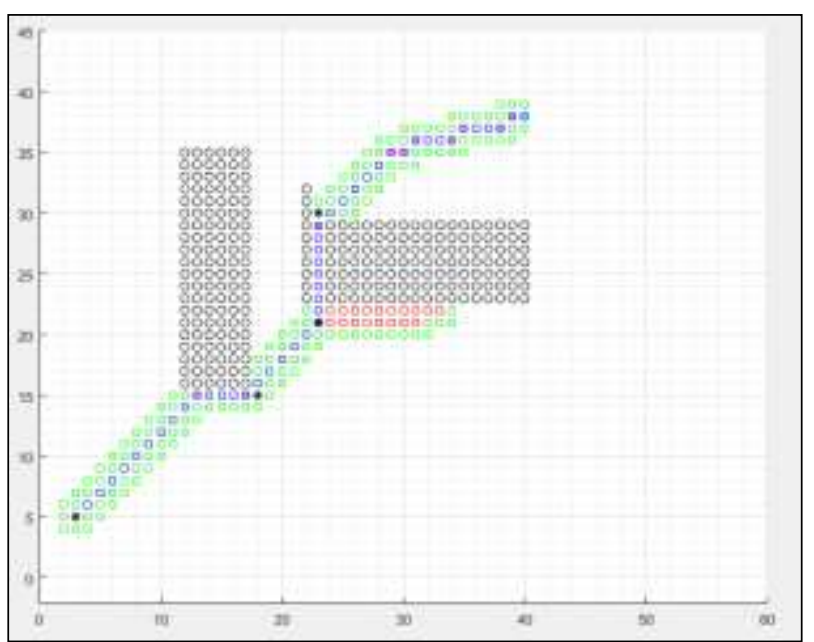

Slika 5. Prikaz smanjenog broja prelomnih tačaka putanje

$\mathrm{Na}$ slici 5 je prikazan konačan broj prelomnih tačaka putanje, i na grafiku, one se nalaze na mestima označenim sa crnim zvezdicama. Kao što se vidi na slici, one prelomne tačke koje se nalaze pored prepreke su pomerene za jedno mesto tako da imaju bolji pogled na ostale prelomne tačke. Ovim pomeranjem, poslednje crne, su preskočene sve tačke koje se nalaze između nje i cilja. Tako da posle ovoga

konačna putanja sadrži u sebi samo 4 tačke, 3 prelomne i 1 željenu poziciju.

\section{REALIZACIJA KRETANJA}

Da bi se izvršila putanja koja je dobijena algoritmom za planiranje, potrebno je da mobilni robot ima realizovano kretanje, u koje spada upravljanje brzinom robota. Pod upravljanjem brzinom se, $\mathrm{u}$ ovom radu, misli na upravljanje u tri faze: prva faza je upravljanje ubrzanjem, druga je održavanje neke predefinisane vrednosti brzine $i$ treća faza je upravljanje usporenjem, tj. kočenjem robota. Ova brzina koja treba konstantno da se održava, dok se ne stigne do treće faze, se naziva brzina krstarenja.

$\mathrm{Na}$ osnovu prethodnog rada [1] izračunati su koeficijenti regulatora brzine koji predstavljaju osnovu za kretanje mobilnog robota.

Sada kada postoji plan kretanja robota kao i regulator brzine, studenti koji se takmiče mogu zahtevati da u različitim delovima putanje robot ima različitu brzinu. To znači da robot treba da zna tačno u kom trenutku treba da počne da usporava ili ubrzava da bi ostvario brzinu koja je zadata za naredni segment putanje. $\mathrm{Na}$ osnovu samo zadatog željenog ubrzanja/usporenja, zadate brzine kretanja i pronađene putanje, robot treba sam da realizuje kretanje, tj. do koje brzine ubrzava, koliko dugo traje druga faza i u kom trenutku počinje treća faza upravljanja brzine da bi na samom početku narednog segmenta putanje imao brzinu koja se u tom segmentu zahteva.

U ovom poglavlju biće opisan način na koji se određuje brzina krstarenja i dužina puta potrebna za usporavanje ili ubrzavanje robota do određene brzine na osnovu dužine puta između početne i krajnje tačke, zadatog ubrzanja/ usporenja, početne i krajnje zadate brzine.

Prvo će biti prikazan i objašnjen trapezni profil brzine. Posle toga biće prikazano kako se određuje maksimalna ostvariva brzina na osnovu dužine puta između početne i krajnje tačke, zadatog ubrzanja/usporenja, početne i krajnje zadate brzine. I poslednje, biće prikazano određivanje dužine puta potrebnog za usporavanje ili ubrzavanje robota da bi se stiglo u krajnju tačku sa željenom brzinom.

\subsection{Trapezni profil brzine}

Jedan od često korišćenih profila brzine je trapezni profil brzine koji se sastoji iz tri faze. Prvu fazu čini ravnomerno ubrzavanje robota od početne do brzine krstarenja.

Drugu fazu čini konstantna brzina krstarenja. I treću fazu čini ravnomerno usporavanje robota od brzine krstarenja do krajnje željene brzine. Na slici 6 je prikazan trapezni profil brzine gde je sa $t_{a}$ označeno vreme ubrzavanja, sa $t_{d}$ vreme usporavanja, $t_{c}$ predstavlja vreme kretanja robota konstantnom brzinom krstarenja, a $T$ je ukupno vreme kretanja.

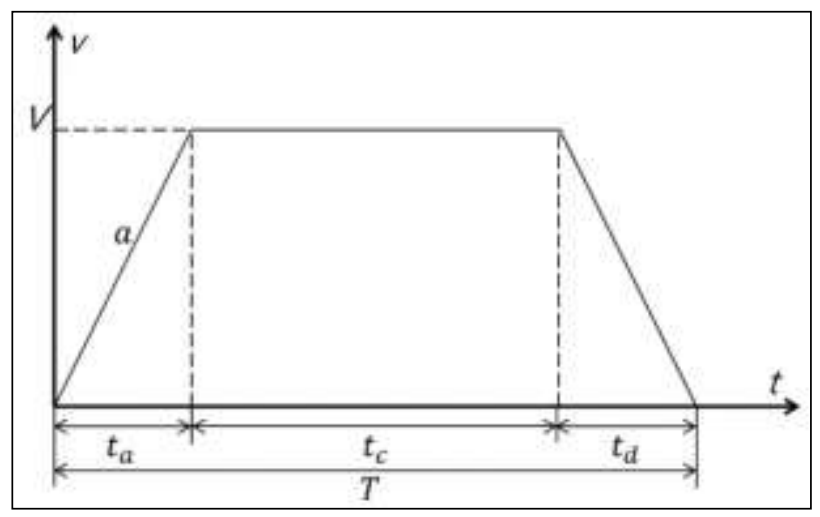

Slika 6. Trapezni profil brzine

\subsection{Određivanje maksimalne ostvarive brzine}

Pre početka kretanja robotu je za svaku tačku putanje predefinisana vrednost brzine koju on treba da ostvari na tom segmentu puta. Tokom kretanja robota može da se desi situacija da mu je predefinisana brzina koju on ne može da dostigne na kratkoj dužini puta, pre nego što bi trebalo da počne da usporava da bi stigao u krajnju tačku sa određenom brzinom. Iz tog razloga je potrebno prvo izračunati maksimalnu brzinu koju robot može da dostigne na određenom segmentu puta i nju uporediti sa zadatom brzinom 
Ako je ta brzina veća od zadate onda trapezni profil brzine napraviti na osnovu te zadate brzine. A ako je ta brzina manja od zadate onda treba postaviti tu maksimalnu brzinu kao brzinu krstarenja, jer svakako veća brzina ni ne može da se dostigne na toj dužini puta. Maksimalna brzina se računa prema formuli (2):

$$
V_{x}=\sqrt{a * l+2 *\left(V_{e n d}^{2}+V_{0}^{2}\right)}
$$

gde je a ubrzanje, $l$ ukupna dužina puta, $V_{\text {end }}$ krajnja brzina i $V_{0}$ početna brzina. $V_{x}$ je maksimalna brzina koja se traži.

\subsection{Određivanje dužine puta potrebnog za usporavanje ili ubrzavanje robota}

Ova dužina puta se računa prema formuli (3).

$$
s=\frac{V_{x}+V_{\text {end }}}{2} * \frac{V_{x}-V_{\text {end }}}{a}
$$

\section{IMPLEMENTACIJA NA MAKETI MOBILNOG ROBOTA}

Implementacija i testiranje je urađeno na maketi mobilnog robota sa tri omnidirekciona točka. Upravljanje kretanjem ove makete mobilnog robota je velikim delom bilo urađeno u prethodnom radu [1], tako da ovaj master rad predstavlja nastavak razvoja kretanja, odnosno planiranja putanje za robota. Ono što je prikazano u ovom radu je primenjivo u opštem slučaju planiranja putanje mobilnih robota. Na slici 7 je prikazana maketa na kojoj je implementiran algoritam za upravljanje kretanjem i algoritam za planiranje putanje koji je opisan u ovom radu. $\mathrm{Na}$ osnovu potreba testiranja ovog rada na maketi je postavljen i optički senzor firme FESTO koji je korišćen za detekciju dinamičkih prepreka.

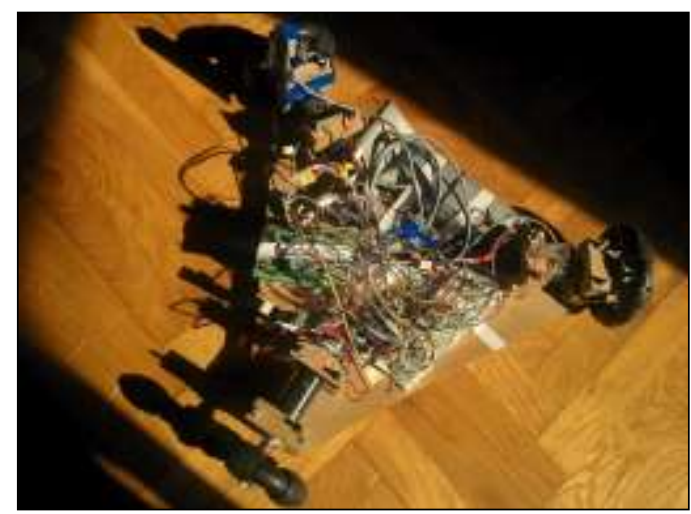

Slika 7. Prikaz makete robota sa tri omnidirekciona točka

Tokom testiranja planiranja putanje se videlo da robot pronalazi istu putanju kao i u simulaciji u zavisnosti od statičkih prepreka i početne i željene pozicije. Posle uspešnog testiranja sa statičkim preprekama postavljenim na različitim mestima, kao i sa različitim željenim pozicijama, postavljen je optički senzor koji detektuje dinamičke prepreke tokom kretanja. Tokom testiranja i sa dinamičkim preprekama se videlo da robot uvek pronalazi putanju do cilja, ukoliko ona postoji.

\section{ZAKLJUČAK}

Zadatak ovog master rada je bila realizacija planiranja putanje i izvršavanje kretanja mobilnog robota u prisustvu statičkih i dinamičkih prepreka. Tokom izrade ovog rada jedno od najzanimljivijih novih znanja koja su naučena su razni algoritmi za planiranje putanje od kojih je izabran A* algoritam kao osnova za traženje putanje za mobilnog robota. Kako se kod ovog algoritma za planiranje putanje kretanje omogućava samo po dijagonali, horizontalno ili vertikalno to znači da, koliki god je velik prostor pretrage, skoro nikad nece biti pronađena baš najkraća putanja između dve tačke.

Čak iako se neke prelomne tačke izbace iz putanje, tačke koje ostanu u novoj putanji su zasnovane na prvobitno pronađenom putu. Što znači da ovo sigurno skraćuje dužinu putanje, ali ne znači da uvek pronalazi najkraći put. Još jedna potencijalna mana je to što najkraći put ne mora uvek biti i najbrži put između dve tačke. A ovo može biti od značaja ako postoji neko određeno vreme za koje robot mora nešto da obavi.

Takođe, mana je i to što robot mora unapred da izračuna celu putanju pre nego što krene u prvu tačku, zato što ako je prostor pretrage mnogo veliki ovo može da potraje nekoliko sekundi što nije poželjno. Zato je prostor pretrage koji je korišćen u ovom zadatku dimenzija 60x40 ćelija, što robotu omogućava da brzo pronađe putanju.

Ovaj rad je nastao iz razloga da bi se studentima, koji se takmiče na nacionalnom takmičenju EUROBOT, olakšalo planiranje putanje mobilnih robota i time olakšalo postizanje boljih rezultata.

Jedno od mogućih unapređenja kretanja i planiranja putanje mobilnih robota bi moglo da bude uvođenje delova putanje koje nisu više samo pravolinijski, npr. uvođenje poluprečnika krivine, što bi omogućilo elegantniji prelazak robota sa jednog pravca kretanja na drugi.

\section{LITERATURA}

[1] Predrag Vasiljević, "Upravljanje kretanjem robotske platforme pogonjene sa tri omnidirekciona točka", Fakultet tehničkih nauka, Univerzitet u Novom Sadu, Oktobar 2017.

\section{Kratka biografija:}

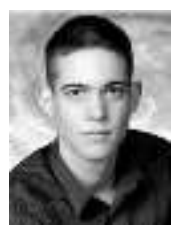

Predrag Vasiljević rođen je u Sremskoj Mitrovici 1994. god. Zvanje diplomiranog inženjera mehatronike stekao je 2017. godine. Master rad na Fakultetu tehničkih nauka iz oblasti Mehatronike odbranio je 2018. godine. kontakt: predrag.v94@gmail.com 